\title{
Experiências de vitimização de jovens adultos Portugueses
}

\author{
Victimization experiences among Portuguese young adults
}

\author{
José Tomás da Silva, Teresa Sousa Machado, José Pacheco Miguel, António Castro Fonseca \\ Faculdade de Psicologia e de Ciências da Educação, Universidade de Coimbra, Portugal
}

\begin{abstract}
Resumo
O fenómeno da vitimização tem sido alvo de uma atenção crescente tanto por parte da comunidade científica como dos cidadãos em geral. Neste estudo iremos examinar a relação entre vitimização e comportamento anti-social em jovens adultos Portugueses (aproximadamente 400 respondentes de ambos os sexos). O grupo composto por vítimas que são simultaneamente transgressores diferiu dos grupos de puras vítimas e de controlo em medidas de delinquência, problemas de externalização, consumo de droga e violência conjugal. $\mathrm{O}$ grupo de vítimas/transgressores é um alvo prioritário para intervenções psicossociais.
\end{abstract}

Palavras-chave: vitimização, jovens adultos, comportamento anti-social, saúde mental

\begin{abstract}
The phenomenon of victimization has been enjoying increasing attention both from the scientific community as from concerned citizens in general. In this study we examine the relationship between victimization and anti-social behavior in Portuguese community young adults (approximately 400 males and females). The group of victims and offenders differ from the groups of pure victims and controls in measures of delinquency, externalizing problems, drug abuse and domestic violence. The group of victims/offenders is a priority target for psychosocial interventions.
\end{abstract}

Keywords: victimization, young adults, antisocial behaviour, mental health

A questão da vitimização tem desfrutado de uma crescente atenção por parte de académicos, profissionais e cidadãos em geral (Caridade \& Machado, 2014; Pratt, Turanovic, Fox, \& Wright, 2014). Os meios de comunicação têm debatido, ultimamente, este tema com alguma frequência e regularidade, conferindo às vítimas uma visibilidade que antes apenas era dispensada ao crime e aos criminosos. Numa análise da situação do crime nos Estados Unidos da América, Burgess e Roberts (2010) afirmaram que "a realidade inquietante sobre o crime nos Estados Unidos e Canadá, hoje, decorre do seu carácter generalizado, da sua natureza frequentemente violenta, e da sua total indiferença a quaisquer tipos de fronteiras” (p. 1). Esta asserção, admitindo a sua generalização a outros países e realidades culturais, leva-nos a concluir que há uma forte possibilidade de qualquer cidadão, em algum momento da sua vida, ser vítima de um qualquer tipo de crime. É este tipo de percepção que, precisamente, surge na base do sentimento de insegurança e de alarmismo social tão frequentemente veiculado pelos meios de comunicação social. Podemos questionarmo-nos sobre a existência de uma base real para estas percepções, ou se, pelo contrário, elas são principalmente consequência de uma maior cobertura dos media. Num trabalho recente Barroso (2007), realça o papel dos media, no caso especial da violência contra as mulheres, resumindo da forma seguinte a situação: “Actualmente, a intrusão crescente dos media na esfera íntima dos indivíduos e das famílias, particularmente da televisão, transmite a imagem de um crescendo de violência social, raramente tendo o cuidado de advertir o público de que muitos dos casos apresentados não são o resultado de um aumento de violência, mas, pelo contrário, de um aumento da acuidade social relativamente a certos actos, dando-lhes visibilidade e retirando-os de universos reservados para o palco da sociedade, como sucede com a violência contra as mulheres nas relações amorosas.” (p. 29)

Sendo verdade que os media, sobretudo os que prosseguem uma linha editorial orientada para a exploração do sensacionalismo, não constituem uma base empírica sólida para aquilatarmos a real prevalência da vitimização numa dada sociedade, também seria igualmente errado ignorarmos esse fundo noticioso e julgarmos que tudo aquilo que lemos na imprensa ou vemos e ouvimos na televisão nada nos informa acerca das dimensões actuais desse problema na nossa sociedade.

Se considerarmos os últimos dados estatísticos disponíveis sobre a vitimização em Portugal teremos de concluir que a maior "acuidade social” acerca do fenómeno, neste caso, não deixa de ter um substrato empírico insofismável. No relatório de 2015 da Associação Portuguesa de Apoio à Vítima (APAV) constam 12.379 processos de apoio concedidos no ano transacto. Destes, “foram acompanhadas 8.889 vítimas directas que foram alvo de 21.541 crimes e ou de outros atos violentos" (APAV, 2015, p. 4). Estes dados podem comparar-se com os relatados por esta associação para o ano de 2013. Neste período o número de processos registados foi de 11.800 , no âmbito dos quais foram atendidas 8.733 pessoas, que foram vítimas directas de 20.642 crimes. Estas cifras revelam que em 2014, comparativamente ao ano precedente, houve um aumento em todos os parâmetros considerados: número de processos $(+4.9 \%)$, de vítimas $(+1.8 \%)$ e de crimes $(+4.4 \%)$. 
O relatório da APAV revela ainda a expressão relativa dos tipos de crimes e outros atos violentos no período de observação. A tipologia de crime preponderante é a dos crimes contra as pessoas ( $n=20.093$, 93.3\%) e, de entre estes, sobressaem os respeitantes à violência doméstica (78.4\%). Seguem-se em termos de frequência, mas com uma expressão relativa significativamente inferior à referida acima, os crimes contra o património ( $n=668$, $3.1 \%$ ), outras formas de violência (v.g., Stalking e Bullying; $n=433$, 2\%). Todas as outras tipologias de crime contempladas no relatório da $\operatorname{APAV~(v.g.,~crimes~}$ contra a vida/sociedade, crimes contra o estado, crimes rodoviários, contra-ordenações e outros crimes) surgem com percentagens inferiores a 1\% (APAV, 2015, pp. 7-9).

As estatísticas apuradas pela APAV podem ser comparadas com as incluídas no relatório anual produzido pelo Sistema de Segurança Interna para o ano de 2014 (Relatório Anual de Segurança Interna, RASI Ano de 2014). De acordo com este relatório e segundo os dados da criminalidade participada em 2014, tendo como fonte a Guarda Nacional Republicana (GNR), a Polícia de Segurança Pública (PSP) e Polícia Judiciária (PJ), contabiliza-se o resultado total de 343.768 participações de natureza criminal, o que, relativamente a 2013, e segundo esta fonte, representa uma diminuição de 24.684 participações, equivalendo a um decréscimo de $6.7 \%$. Uma análise mais detalhada, tendo por base a repartição das participações por grande categoria criminal, revela uma diminuição em qualquer uma das categorias consideradas, oscilando o decréscimo entre 20.2\% (Crimes contra a vida e a sociedade) e 1.3\% (Crimes contra as pessoas). A desagregação dos dados, tendo em conta a criminalidade mais participada, mostra que houve decréscimo na maioria das categorias de crime, designadamente, e por ordem decrescente, crime de furto de "metais não preciosos" (-37.2\%), crime de condução sem habilitação legal (-18.7\%), crime de "condução de veículo com taxa de álcool superior a 1.2 g/l” (-15.7\%) e crime de furto "em residência com arrombamento escalamento ou chave falsa” (-13\%). No entanto, algumas participações de crimes aumentaram comparativamente a 2013. Os crimes de furto (v.g., por carteirista e de oportunidade/ de objetos não guardados), por exemplo, aumentaram 36.3\% e 9.2\%, respetivamente. Outra tipologia onde se verificou um ligeiro aumento (mais 31 participações, equivalente a $+0.1 \%$ ) foi a de crime de violência doméstica "contra conjugue ou análogos”, concluindo-se, por isso, que “o crime de violência doméstica continua a apresentar um elevado número de participações.” (RASI, 2015, p. 2). A existência de discrepâncias na medição do crime nos dois sistemas consultados, comprováveis para categorias de crimes comensuráveis, não resulta apenas de diferenças ao nível da definição dos crimes entre os vários operadores, embora, estas existam em vários casos. O fenómeno é mais geral e a existência de discrepâncias entre os diferentes sistemas de medida está amplamente documentado na vitimologia (Burgess \& Roberts, 2010). Qualquer das principais fontes usadas para medir o crime (v.g., Relatórios dos Órgãos de Polícia Criminal; Inquéritos (de auto-resposta) de crimes e de vítimas) oferecerá alguma vez uma resposta definitiva ao número de vítimas do crime porque sempre ficará a questão acerca de casos não reportados e não reconhecidos. As estimativas que extraímos de inquéritos baseados nos auto-relatos são, em geral, mais elevadas do que as que se obtêm das estatísticas resultantes das participações conhecidas pelas autoridades. Diferenças significativas têm sido inclusive encontradas mesmo quando se recorre a métodos similares (por exemplo, auto-resposta). Numa análise da vitimização infantil e juvenil, Finkelhor (2007), por exemplo, mostra existirem discrepâncias importantes entre os dados obtidos através da administração do National Crime Victimization Survey (NCVS), a autoridade máxima na medição da vitimização, em geral, nos Estados Unidos da América (EUA), e o Development Victimization Survey (DVS), em categorias de crimes equivalentes. Em Portugal os dados sobre vitimizações provenientes de estudos por inquéritos de auto-resposta são ainda escassos e este trabalho procura colmatar a falta de informação nesta área.

\section{Vitimização nos jovens adultos}

A investigação em vitimologia tem consistentemente mostrado que não há um perfil típico da vítima do crime. Pessoas de todas as idades, raças, etnias, e classes socioeconómicas estão igualmente sujeitas a serem alvos de ataques criminosos de um tipo ou de outro. Todavia, baseando-se nas estatísticas produzidas nos EUA pelo Federal Bureau of Investigation (FBI), Burgess e Roberts (2010) concluem que nem todos os grupos têm igual probabilidade de ser vítima de crime. Por exemplo, os dados, desse país, revelam que os jovens negros, com idades entre os 16 e os 24 anos, e que habitam em áreas urbanas com elevada taxa de criminalidade, constituem o grupo com maior possibilidade de ser vítima de crime.

Além disso, a literatura mostra que aspectos relacionados com o estilo de vida, o local de residência e a raça parecem ser preditores importantes de quem correrá maior risco de ser vítima de crime.

Os jovens na fase de transição para a idade adulta, também designados como "adultos emergentes" (Arnett, 2000), isto é, os indivíduos que estão na faixa etária que se estende dos 18 aos 25 anos de idade, pelas suas características peculiares, nomeadamente por se encontrarem numa fase de elevada actividade de exploração e de construção da identidade pessoal, apresentam um estilo de vida que, comparativamente a outros grupos etários, os deixa mais vulneráveis a experiências de vitimização (e.g., exposição acrescida a riscos derivados de uma vida nocturna mais frequente). Alguns tipos de vitimização menos frequentemente estudados, como é o caso da violência no namoro e nas relações íntimas com os parceiros podem ser também, pelo menos em teoria, mais prevalentes nesta fase da vida, já que, como se sabe, é nesta idade que as/os jovens intensificam os comportamentos de selecção de um potencial cônjuge (v.g., Arnett, 2000; Halpern-Meeking, Manning, Giordano \& Longmore, 2013) e, consequentemente, estão mais expostos a experiências de violência no namoro. 
As estatísticas resultantes dos casos conhecidos pelas autoridades (OPC) ou das associações especializadas (APAV) não nos informam sobre variedade e a prevalência da tipologia de vitimizações para diferentes segmentos da população. Por exemplo, o Relatório Anual 2014, da APAV, mostra que dos utentes que reportaram crimes a esta associação, 471 tinham idades compreendidas entre os 18 e os 24 anos, que constituem, grosso modo, as idades que balizam o grupo dos jovens adultos, todavia, não são apresentadas estatísticas a respeito de tipos de crimes para este grupo etário específico.

$\mathrm{Na}$ literatura, porém, encontramos expressa com frequência a ideia de que os adolescentes mais velhos e os jovens adultos, ou seja, todos aqueles que se encontram na faixa etária dos 16 aos 25 anos, apresentam um risco acrescido para serem alvo de violência não letal por parte dos seus parceiros (Arriaga \& Foshee, 2004). Estatísticas obtidas nos EUA apontam para taxas anuais de abuso físico e psicológico de adolescentes, no âmbito específico do namoro de, aproximadamente, $10 \%$ a 30\%, respetivamente (Eaton, Davis, Barrios, Brener \& Noonan, 2007). Os desafios e as tarefas de desenvolvimento desta fase da vida contribuem, de algum modo, para que adolescentes e os adultos emergentes estejam particularmente vulneráveis a este tipo de acontecimentos. Como referem Chronister e Alderondo (2012), o período do final da adolescência e da emergência da adultez está especialmente associado com a exploração da identidade, a instabilidade, a experimentação com o uso de substâncias ilícitas, relações românticas e responsabilidades parentais que, afinal, colocam os jovens adultos numa situação de risco elevado para a violência.

Um dos objetivos deste trabalho é, face às lacunas detetadas, apresentar estimativas de vitimização derivadas das respostas de jovens adultos da comunidade a um questionário de auto-resposta aplicado no contexto do estudo longitudinal de Coimbra (ELC, vide Simões, Ferreira, Fonseca, \& Rebelo, 1995). Mais especificamente, queremos, por um lado, conhecer a intensidade (incidência) de vitimizações na amostra total e ainda em função do sexo e, por outro, o grau de prevalência de diferentes tipos de vitimização, tanto na amostra total como por sexo.

\section{Vitimização e comportamento anti-social}

Um resultado bastante consistente das investigações baseadas em inquéritos psicossociais é o da coexistência de comportamentos anti-sociais e de vitimização nos mesmos indivíduos. Como referem Pratt et al. (2014), os criminólogos há muito tempo que observaram uma correlação significativa entre ofensas e vitimização. Por exemplo, Lauritsen, Laub e Sampson (1992) verificaram que $45 \%$ dos jovens delinquentes da sua amostra também reportavam vitimização, enquanto a percentagem era apenas de $12 \%$ nos não delinquentes. Esta cormobilidade tem sido, aliás, reportado em estudos efectuados em diversos países, diferentes épocas, diferentes grupos e diferentes contextos. Além disso, a co-ocorrência do comportamento anti-social e da vitimização parece manter-se independentemente do tipo de conduta delinquente (v.g., crime contra pessoas ou contra propriedade) ou da metodologia utilizada (v.g., inquéritos de vitimização ou escalas de autoavaliação de delinquência). Menos consensuais, porém, têm sido as explicações avançadas para essa elevada taxa de sobreposição entre vítimas e agressores, embora as propostas não escasseiem. Uma hipótese frequentemente referida é a de que agressores e vítimas se encontram frequentemente expostos aos mesmos factores de risco (Jennings, Piquero, \& Reingle, 2012). Uma tal explicação está de acordo com as concepções contemporâneas do crime preconizadas pela teoria das “actividades de rotina.” Esta teoria é um subdomínio da teoria da oportunidade do crime ou, mais genericamente das concepções da "criminologia ambiental” e salienta, sobretudo, o impacto das situações em torno do crime (v.g., é mais provável uma pessoa ser roubada ou ser vítima de assalto no parque do que em sua casa, admitindo que aí adoptou as medidas de segurança apropriadas). Ainda uma outra hipótese é a do princípio da homogamia de acordo com o qual as vítimas correm maiores riscos de ser agredidas na medida em que contactam amiúde com os perpetradores (Tillyer \& Wright, 2014). O princípio da homogamia, derivado da teoria das actividades de rotina/estilo de vida, sugere que o risco de vitimização dos indivíduos está relacionado com a frequência com que estes se associam, ou estão em contacto, com membros de grupos demográficos que incluem uma parcela desproporcionada de transgressores. Nesse sentido, alguns autores, têm sugerido que as vítimas e os agressores são muitas vezes as mesmas pessoas. Sabe-se, por exemplo, que as vítimas de crime têm maior probabilidade do que as não vítimas de confessarem envolvimentos em actividades desviantes.

Estudos que examinaram um leque mais diversificado de vitimizações em amostras da comunidade e que não se limitam ao contexto estudantil são ainda escassos entre nós. Outro objetivo deste estudo consiste em analisar a relação entre vitimização e comportamentos anti-sociais, tendo em consideração o grau de sobreposição de vitimização-transgressão presente nos respondentes da nossa amostra. Para efeitos desta análise constituíram-se três grupos: (1) vítimas-transgressores, (2) vítimas puras e (3) não-vítimas. A hipótese de investigação é de que o primeiro grupo diferirá significativamente dos outros dois grupos nas medidas do comportamento anti-social estudadas.

\section{Método}

\section{Participantes}

Durante o ano académico de 1992-93 iniciou-se em Coimbra um estudo que envolvia uma amostra representativa dos alunos que nessa altura frequentavam o $2^{\circ}, 4^{\circ}$ e $6^{\circ}$ anos das Escolas Públicas desse concelho (Simões et al., 1995). Os dados que aqui serão discutidos dizem respeito apenas à coorte mais jovem, ou seja, aos alunos do $2^{\circ}$ ano. Os membros dessa coorte (inicialmente 240 rapazes e 205 raparigas) foram avaliados até agora 
cinco vezes, a primeira quando tinham 7-8 anos de idade, e a última quando eles tinham em média 26-27 de idade (final do período da adultez emergente). Durante a última avaliação foi possível entrevistar cerca de $86 \%$ dos elementos da amostra inicial $(n=417)$, dos quais 219 (49.2\%) são do sexo masculino e 197 (44.3\%) do sexo feminino (um participante não respondeu a esta questão). A média das idades é de 26.6 anos ( $D P=1.1$ anos), oscilando os valores entre os 25-33 anos. No que diz respeito ao estado civil a maioria ( $n=268$, ou seja, $66 \%)$ nunca casou, $n=74$ (18.2\%) declara-se casada(o), a viver com o conjugue, apenas 7 estão divorciados (1.7\%) e 57 (ou seja, 14\%) declaram outra situação (vários respondentes não forneceram informação válida na variável). Em termos de habilitações literárias (considerando apenas as respostas válidas a esta questão) constatamos que 109 têm o $9^{\circ}$ ano ou inferior (28\%), 90 (ou seja, 23.1\%) completaram o ensino secundário e 190 (i.e., 48.2\%) algum tipo de formação superior (v.g., bacharelato, licenciatura, mestrado ou doutoramento).

\section{Instrumentos}

Da lista de instrumentos utilizados nesta última fase do estudo, faziam parte uma escala de delinquência e um inquérito de vitimização. A primeira (Self-Reported Delinquency, SRD) inclui 54 itens, relativos a diversas transgressões e consistiu numa adaptação de um instrumento construído, originalmente, por Loeber, Farrington, Stouthamer-Loeber e Van Kammen (1998), no seu estudo de S. Petersburgo (EUA). A cada uma dessas perguntas os participantes respondiam se o comportamento referido ocorreu alguma vez na vida (Sim/Não) e ainda se ocorreu no último ano (nunca $=0$, uma ou duas vezes $=1$ e várias vezes $=2$ ). Nove desses itens foram utilizados especificamente para constituir uma escala de consumo de droga.

O segundo instrumento, construído especificamente para esta investigação, inclui 19 perguntas relativas a outras tantas experiências específicas de vitimização (v.g., danificação de propriedade, agressões ou ameaças) ocorridas alguma vez na vida. A cada item o participante podia responder $\operatorname{Sim}=1$ ou Não $=0$. Além disso, perguntava-se aos participantes se, na sequência das vitimizações sofridas, tinham apresentado queixa às autoridades ou se tinham necessitado de ajuda especializada (v.g., médica, psicológica ou social).

Outras medidas utilizadas na última avaliação destes jovens adultos e directamente relacionadas com o esclarecimento das questões aqui em apreço foram o Inventário de Problemas do Comportamento de Achenbach, na sua versão para adultos (Achenbach \& Rescorla, 2003) e uma escala de violência conjugal (construída especificamente para este estudo e directamente inspirada numa medida semelhante utilizada no estudo longitudinal de Dunedin, na Nova Zelândia).

\section{Resultados}

Na Figura 1 apresenta-se a variedade (número e percentagem) das vitimizações $(0 \mathrm{a}>5)$ sofridas pelos participantes deste estudo alguma vez na vida.

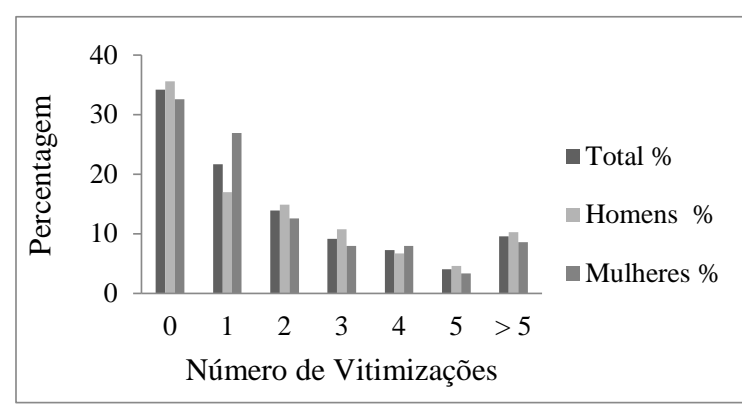

Figura 1. Número de vitimizações sofridas alguma vez na vida

Aproximadamente um terço da amostra (34.2\%) não reportou qualquer experiência de vitimização, 52.1\% dos participantes afirmaram ter experimentado entre uma e cinco vitimizações; e 9.6\% dizem ter sido alvo entre seis e catorze vitimizações. Os números são muito semelhantes quando a análise incide sobre as frequências calculadas separadamente para os homens e para as mulheres. A média das vitimizações é ligeiramente mais baixa no grupo dos rapazes $(M=2.1)$ do que no grupo das raparigas $(M=2.2)$, embora esta diferença não seja estatisticamente significativa $(p>.05)$.

Na Tabela 1, apresentam-se as ocorrências dos cinco principais tipos de vitimização referidos no total da amostra.

Tabela 1.

Prevalência (em percentagem) dos cinco principais tipos de vitimização na amostra total

\begin{tabular}{lc}
\hline Vitimização & $\%$ \\
\hline Presenciou agressões físicas ou verbais contra outros & 25,6 \\
Foi vítima de roubo sem violência & 20,6 \\
Viu outros à sua volta serem acusados sem razão & 18,1 \\
Tentaram ridicularizá-lo, humilhá-lo, desacreditá-lo & 15,2 \\
Tentaram roubar-lhe alguma coisa, usando a força & 13,1 \\
\hline
\end{tabular}

As vitimizações com maior prevalência estão em geral concentradas em eventos que podemos considerar menos graves.

Por sua vez, entre as vitimizações com menor baixa ocorrência encontramos as que apresentam maior gravidade (v.g., experiência de abuso sexual; ameaças ou chantagens com vista a extorquir dinheiro ou outros favores: $3.1 \%$ e $3.4 \%$, respetivamente). Noutras análises que efetuámos (não apresentadas neste trabalho) pudemos constatar que o padrão de vitimização é muito parecido para ambos os sexos (vide Silva \& Fonseca [2014] para uma apresentação completa da prevalência de cada um dos dezanove acontecimentos de vitimização incluídos no questionário).

Finalmente, compararam-se as médias dos três subgrupos - vítimas/transgressores, vítimas e não vítimas - nas variáveis de delinquência (auto relatada), problemas de externalização (Achenbach), consumo de droga e violência doméstica. O primeiro subgrupo registou médias mais elevadas do que os outros dois grupos em todas as dimensões avaliadas $(p<.05)$. Os 
respondentes (apenas) vítimas não diferem das não vítimas nos comportamentos delinquentes, consumo de droga e violência conjugal. Todavia, as vítimas $(M=7.5)$ distinguem-se das não vítimas $(M=5.9)$ nos comportamentos de externalização.

\section{Discussão}

A percepção, por parte dos cidadãos, de um crescendo da violência tem vindo a suscitar um medo real ou simplesmente imaginário, que se adensa, não somente com a multiplicação dos actos violentos, mas também pelo efeito amplificador dos serviços noticiosos, especialmente nos difundidos pelos vários canais de televisão. Uma questão importante é saber se há uma base real para as percepções subjetivas dos cidadãos. A maioria dos participantes, neste estudo, afirmou ter sido vítima (ou ter presenciado vitimizações), alguma vez na vida. A idade de transição para a vida adulta parece, assim, constituir um período de risco elevado de vitimização. De qualquer modo, o facto de a grande maioria desta amostra confessar ter sofrido alguma vez uma ou mais vitimizações, não significa que se esteja perante um aumento incontrolado da criminalidade nem perante um sentimento generalizado de insegurança na comunidade. De facto, uma análise mais detalhada dos resultados mostra que a ocorrência de cada vitimização é bastante baixa (ou mesmo muito baixa, no caso das vitimizações mais graves). Uma outra conclusão interessante desta investigação foi a de que as vítimas que são também transgressores constituem um subgrupo muito mais problemático do que os participantes que foram vítimas, mas não agressores, e do que os seus pares que não reportaram qualquer vitimização. Em particular, verificou-se que aquele subgrupo reportava mais delinquência, mais consumo de droga e mais problemas de saúde mental do que os outros dois grupos. Seria interessante, como afirmámos noutro lugar (Silva \& Fonseca, 2014), analisar em futuras avaliações da mesma coorte se essas diferenças se mantêm, se agravam ou desaparecem com a idade e com novas experiências de vida. O problema da sobreposição da conduta delinquente e da vitimização é um domínio que merece uma maior atenção dos investigadores, devido às relevantes implicações teóricas e práticas que daí podem advir.

\section{Referências}

Achenbach, T., \& Rescorla, L. (2003). Manual for the ASEBA adult forms and profiles. Burlington, VT: University of Vermont.

Arnett, J. (2000). Emerging adulthood: A theory of development from the late teens through the twenties. American Psychologist, 55, 469-480.

Arriaga, X., \& Foshee, V. (2004). Adolescent dating violence: Do adolescents follow in their friend's, or their parent's, footsteps? Journal of Interpersonal Violence, 19, 162-184.

APAV (2015). Estatísticas APAV relatório anual 2014. Lisboa: APAV (www.apav.pt/estatisticas).
Barroso, Z. (2007). Violência nas relações amorosas. Lisboa: Edições Colibri.

Burgess, A. \& Roberts, A. (2010). Crime and victimology. In A. Burgess, C. Regher, \& A. Roberts. (Eds.). Victimology: Theories and applications (pp. 1-30). London: Jones and Bartlett Publishers.

Caridade, S. \& Machado, C. (2014). Violência nas relações juvenis de intimidade: Uma revisão da teoria, da investigação e da prática. Psicologia, 27, 91-113.

Chronister, K. \& Aldarondo, E. (2012). Partner violence victimization and perpetration: Developmental and contextual implications for effective practice. In $\mathrm{N}$. Fouad (Ed.). Handbook of counseling psychology (pp. 125-151). Washington, DC: APA.

Eaton, D., Davis, K., Barrios, L., Brener, N., \& Noonan, R. (2007). Associations of dating violence victimization with lifetime participation, co-occurrence, and early initiation of risk behaviors among U.S. high school students. Journal of Interpersonal Violence, 22, 585-602.

Finkelhor, D. (2007). Development victimology. In R. Davis, A. Lurigio, \& S. Herman (Eds.). Victims of crime (pp. 9-34). Thousand Oaks, CA: Sage.

Halpern-Meekin, S., Manning, W., Giordano, P., \& Longmore. M. (2013). Relationship churning, physical violence and verbal abuse in young adult relationships. Journal of Marriage and Family, 75, 2-12.

Jennings, W., Piquero, A., \& Reingle, J. (2012). On the overlap between victimization and offending: a review of the literature. Aggression and Violent Behavior, 17, 16-26.

Lauritsen, J., Laub, J., \& Sampson, R. (1992). Conventional and delinquent activities: implications for the prevention of violent victimization among adolescents. Violence and Victims, 7, 91-108

Loeber, R., Farrington, D., Stouthamer-Loeber, M., \& Van Kammen, W. (1998). Antisocial behaviour and mental health problems: Explanatory factors in childhood and adolescence. London: LEA.

Pratt, T., Turanovic, J., Fox, K., \& Wright, K. A. (2014). Self-control and victimization: A meta-analysis. Criminology, 52, 87-116.

Silva, J. T. \& Fonseca, A. C. (2014). Experiências de vitimação em jovens adultos Portugueses. In A. C. Fonseca (Ed.). Jovens adultos (pp. 201-261). Coimbra: Almedina.

Simões, A., Ferreira, J. A., Fonseca, A. C. \& Rebelo, J. A. (1995). Um estudo dos distúrbios do comportamento e dificuldades de aprendizagem no ensino básico: opções metodológicas. Revista Portuguesa de Pedagogia, XXIX(3), 55-68.

Sistema de Segurança Interna (2015). Relatório Anual de Segurança Interna 2014 (http://www.portugal.gov.pt/). Tillyer, M. \& Wright, E. (2014). Intimate partner violence and the victim-offender overlap. Journal of Research in Crime and Delinquency, 51, 29-55. DOI: DOI: $10.1177 / 0022427813484315$ 